\title{
BULK MODULUS OF II-VI AND III-V SEMICONDUCTORS
}

\author{
Madhu Sudan Dutta, Mritunjai Kr. Pathak, Rajednra Nath Sinha, Ashok Kumar Gupta and Parmanand \\ Mahto
}

University Department of Physics, Vinoba Bhave University, Hazaribag, Jharkhand, India

Abstract: A semi-empirical formula has been proposed in this paper to calculate bulk modulus of Zinc blende structured III -V and II-VI semiconductors in terms of bond hardness. Bond hardness is calculated using valence electron number, covalent / ionic radius and co-ordination number of bonded atoms of the tetrahedral semiconductors. To calculate the resultant bond hardness covalent and ionic contributions to bond hardness are separately calculated. Results obtained using the proposed relation agrees well with the experimental and theoretical values of other researchers.

Keywords: bond hardness, atomic stiffness, bulk modulus, ionicity.

\section{INTRODUCTION}

The bulk modulus of binary semiconductors and their alloys has been extensively investigated. It has been one of the important parameters for studying physical and mechanical properties [1-6] of materials systems. Since it is related to deformation against external force of materials its measurement is useful for microhardness and mechanical test of materials. The study of bulk modulus of anisotropic materials is essential for coating materials in photovoltaic application, fiber reinforced composites, polycrystalline textured materials, biological tissues etc [7]. As the bulk modulus involves change in volume and stress (pressure) developed and is sensitive to variation in the equation of state, it has provided basis for study of earth deep interior [8]. Various researchers have proposed empirical relations for calculating bulk modulus of binary semiconductors [9-11]. But the calculated and reported results are not in good agreement with available experimental values. The reported values also differ widely among themselves in some cases. This gives scope for further investigation on calculation of bulk modulus of binary semiconductors. This paper is an attempt in this direction in which a new relation has been proposed for calculating bulk modulus of elemental and binary semi-conductors. we have made an attempt to propose a correlation between bulk modulus and bond hardness of II-VI and III-V binary semiconductors.

\section{THEORETICAL APPROACH}

The tetrahedral semiconductors (II-VI and III-V) are partially ionic. It is evident from the recent studies [12-15] on bulk modulus and harndess of covalent and ionic crystals that the ionic materials always posses relatively lower hardness [16] and superhard materials have strong covalent bonds; high valence electron density, large modulus and large strength [17]. But the earlier model of ionicity [18] exhibit the trend opposite to above mentioned fact. Recently, we have proposed a new model of ionicity [19] the results of which are in conformity with the trend of variation of hardness/bulk modulus with ionicity. So we have utilised the ionicity/ covalency, wherever required from our model.

It is argued that bond hardness must reflect its signature in microhardness. In other words microhardness should increase (decrease) with increase (decrease) of bond hardness. But the bond between atoms of a tetrahedral semiconductor being partially ionic and partially covalent, we intend to compute the bond hardness considering the covalent and the ionic contributions separately and then obtaining the resultant of them. In this attempt, we using Li and Xue [28] define the electron holding energy of atoms with a covalent bond as

$\mathrm{E}_{\mathrm{c}}=\mathrm{Z} / \mathrm{R}^{\mathrm{c}}$

and the electron holding energy of an atom with an ionic bond as

$\mathrm{E}_{\mathrm{i}}=\mathrm{Z} / \mathrm{R}^{\mathrm{i}}$

where $\mathrm{Z}$ is the number of valence electrons and $\mathrm{R}^{\mathrm{c}(\mathrm{i})}$ is the covalent (ionic) radius of the $\mathrm{i}^{\text {th }}$ atom. Accordingly, the atomic stiffness is expressed as

$$
S^{c(i)}=E_{c(i)} /\left(R^{c(i)}\right)^{3}
$$

The hardness of the covalent(ioninc) bond $a-b$ of a compound ' $a b$ ' defined as the electron- holding energy of the bond per unit volume, is given by the geometric mean of atomic stiffness per bond of atoms, i.e

$$
\begin{aligned}
& H_{a b}^{c(i)}=\left(S_{a}^{c(i)} S_{b}^{c(i)} / C_{N a} C_{N b}\right)^{0.5}= \\
& \left(Z_{a} Z_{b} / C_{N a} C_{N b}\right)^{0.5} /\left(R_{a}^{c(i)}\right)^{2}\left(R_{b}^{c(i)}\right)^{2}
\end{aligned}
$$

where $\mathrm{C}_{\mathrm{Ni}}(\mathrm{i}=\mathrm{a}, \mathrm{b})$ is the co-ordination number of the $\mathrm{i}^{\text {th }}$ atom. Covalent and ionic contribution to bond hardness of II-VI and III-V semiconductors was calculated using Eq. (4). The resultant bond hardness is given by

$$
H_{a b}=H_{a b}^{c} f_{c}+H_{a b}^{i} f_{i}
$$

where $H_{a b}^{c}$ is the covalent contribution to the bond hardness, $H_{a b}^{i}$ is the ionic contribution to the bond hardness, $f_{c}$ is the covalency and $f_{i}$ is the ionicity of the bond a-b.. The value of ionicity $\left(f_{i}\right)$ and covalency $\left(f_{c}\right)$ have been obtained from our newly proposed model [26], and accordingly the resultant bond hardness has been 
ICAASET-2021, 20-21 May, 2021, K.R. Mangalam University, Gurugram

International Journal of Technical Research \& Science (Special Issue) ISSN No.:2454-2024 (online)

calculated. The available experimental values of bulk modulus (Bin GPa) of III-V and II-VI semiconductors were then plotted against the computed bond hardness, $\mathrm{H}_{\mathrm{ab}}$ (in GPa) (Eq. 5). Plots are linear (Fig. 1 and 2) with correlations of 0.9915 and 0.9923 respectively for III-V and II-VI semiconductors indicating strong linear dependence of bulk modulus on bond hardness.

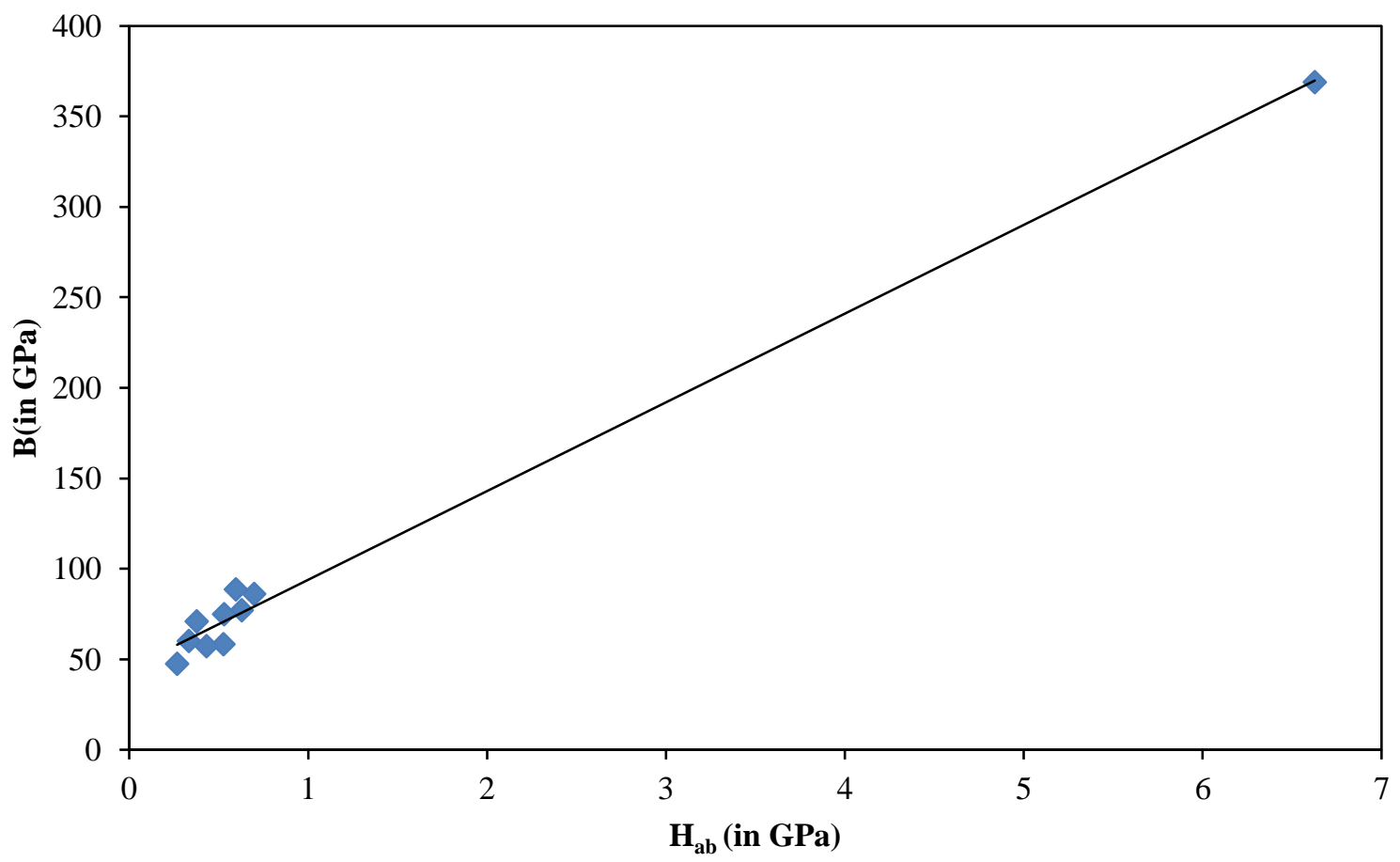

Fig. 2.1 Plot of bulk modulus, B versus bond hardness, $\mathrm{H}_{\mathrm{ab}}$ for III-V semiconductors

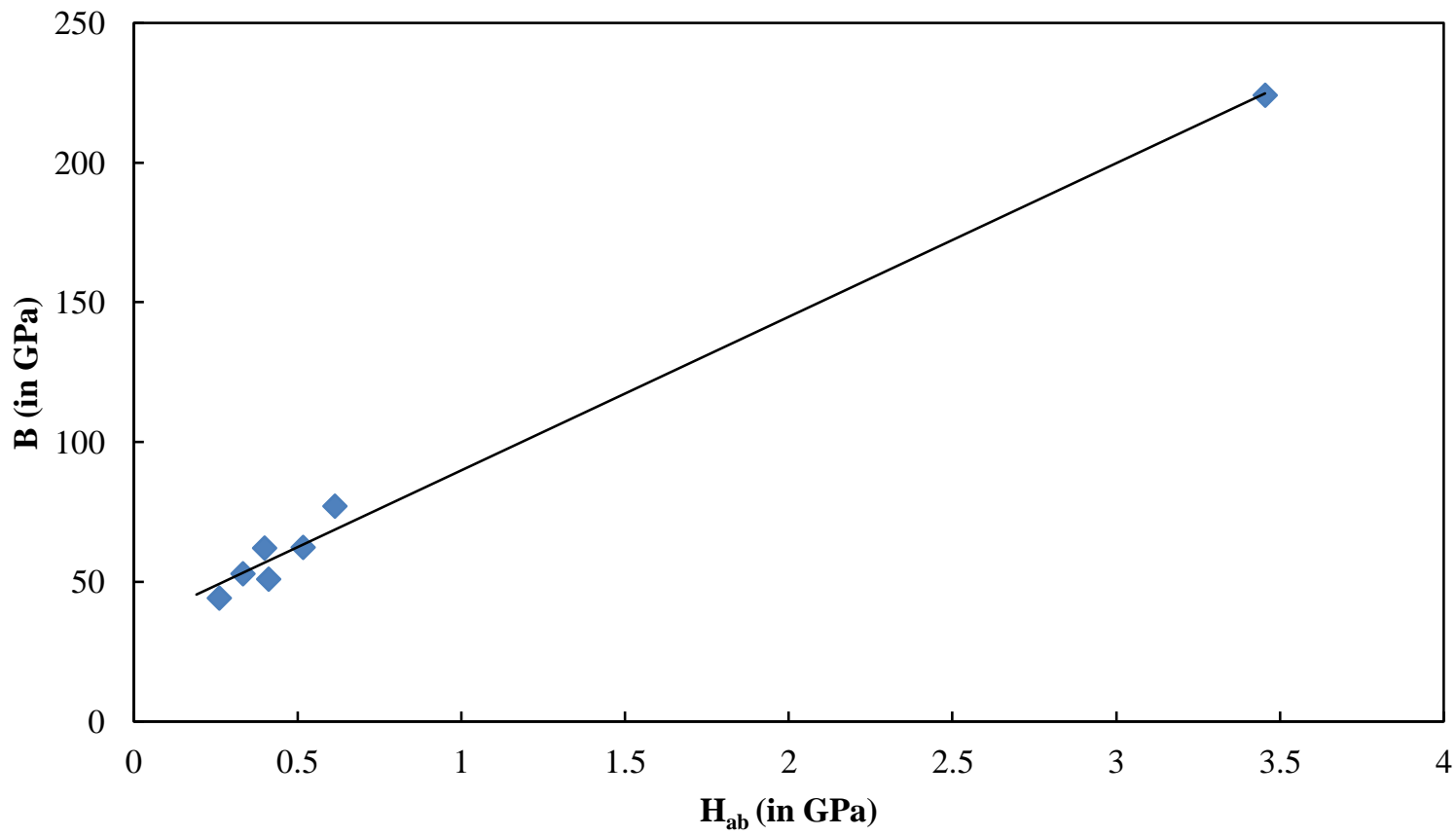

Fig. 2.2 Plot of bulk modulus, $\mathrm{B}$ versus bond hardness, $\mathrm{H}_{\mathrm{ab}}$ for II-VI semiconductors

Accordingly, the following relation is proposed for bulk modulus in terms of bond hardness

$$
\mathrm{B}=\mathrm{a} \mathrm{H}_{\mathrm{ab}}+\mathrm{b}
$$

Where $a$ and $b$ are the fitting parameters. The values of ' $a$ ' and ' $b$ ' are proposed as 48.71, 45.03 and55.09, 34.557 for group III-V and II-VI semiconductors respectively. This relation has been utilised in the prediction of bulk modulus of other III-V and II-VI semiconductors for which the experimental values to the best of our knowledge is not available.

\section{RESULTS AND DISCUSSION}

Calculated values bond hardness, $H_{a b}$ along with $f_{i}$ and $f_{c}$ of the systems are presented in Table I. Bulk modulus of semiconductors belonging to III-V and II-VI are given in Table II. For comparison experimental and the reported values are also given. Values of bulk modulus obtained using proposed Eq.(6) are in reasonable agreement with the experimental values. 
ICAASET-2021, 20-21 May, 2021, K.R. Mangalam University, Gurugram

International Journal of Technical Research \& Science (Special Issue) ISSN No.:2454-2024 (online)

Table-3.1 Calculated Bond Strength $\left(H_{a b}\right.$ in GPa) using Eq. (5), bond ionicity $\left(f_{i}\right)$ and bond covalency $\left(\mathbf{f}_{v}\right)$ for Gr. III-V and II-VI semiconductors

\begin{tabular}{|c|c|c|c|c|}
\hline \multicolumn{2}{|c|}{ Systems } & $\begin{array}{l}f_{i} \\
\text { Ref. [21] }\end{array}$ & $\begin{array}{l}f_{c} \\
\text { Ref. [22] }\end{array}$ & $\begin{array}{l}\mathrm{H}_{\mathrm{ab}} \\
\text { (in GPa) } \\
\text { (Eq.5) }\end{array}$ \\
\hline \multirow[t]{16}{*}{ III-V } & $\mathrm{BN}$ & 0.158 & 0.842 & 6.627 \\
\hline & $\mathrm{BP}$ & 0.227 & 0.773 & 4.898 \\
\hline & BAS & 0.243 & 0.757 & 4.650 \\
\hline & $\mathrm{BSb}$ & 0.276 & 0.724 & 4.175 \\
\hline & AlN & 0.216 & 0.784 & 1.228 \\
\hline & AlP & 0.298 & 0.702 & 0.697 \\
\hline & AlAs & 0.312 & 0.688 & 0.628 \\
\hline & $\mathrm{AlSb}$ & 0.348 & 0.652 & 0.527 \\
\hline & $\mathrm{GaN}$ & 0.224 & 0.776 & 1.177 \\
\hline & $\mathrm{GaP}$ & 0.297 & 0.703 & 0.598 \\
\hline & GaAs & 0.314 & 0.686 & 0.532 \\
\hline & $\mathrm{GaSb}$ & 0.348 & 0.652 & 0.431 \\
\hline & InN & 0.262 & 0.738 & 0.749 \\
\hline & InP & 0.329 & 0.671 & 0.377 \\
\hline & InAs & 0.343 & 0.657 & 0.334 \\
\hline & InSb & 0.375 & 0.625 & 0.268 \\
\hline \multirow[t]{15}{*}{ II-VI } & $\mathrm{BeO}$ & 0.453 & 0.547 & 3.454 \\
\hline & $\mathrm{BeS}$ & 0.573 & 0.427 & 2.288 \\
\hline & $\mathrm{BeSe}$ & 0.596 & 0.404 & 2.003 \\
\hline & BeTe & 0.637 & 0.363 & 1.674 \\
\hline & $\mathrm{ZnO}$ & 0.547 & 0.453 & 1.081 \\
\hline & $\mathrm{ZnS}$ & 0.626 & 0.374 & 0.615 \\
\hline & $\mathrm{ZnSe}$ & 0.647 & 0.353 & 0.517 \\
\hline & $\mathrm{ZnTe}$ & 0.679 & 0.321 & 0.411 \\
\hline & $\mathrm{CdO}$ & 0.602 & 0.398 & 0.721 \\
\hline & $\mathrm{CdS}$ & 0.660 & 0.340 & 0.399 \\
\hline & $\mathrm{CdSe}$ & 0.676 & 0.324 & 0.332 \\
\hline & $\mathrm{CdTe}$ & 0.705 & 0.295 & 0.261 \\
\hline & $\mathrm{HgS}$ & 0.661 & 0.339 & 0.305 \\
\hline & $\mathrm{HgSe}$ & 0.678 & 0.322 & 0.249 \\
\hline & $\mathrm{HgTe}$ & 0.705 & 0.295 & 0.191 \\
\hline
\end{tabular}


ICAASET-2021, 20-21 May, 2021, K.R. Mangalam University, Gurugram

International Journal of Technical Research \& Science (Special Issue) ISSN No.:2454-2024 (online)

Table-3.2 Bulk Modulus, B (in GPa) of Gr. III-V and II-VI semiconductors obtained from bond hardness [Eq. (6)] along with experimental and reported values

\begin{tabular}{|c|c|c|c|c|c|c|c|}
\hline \multicolumn{2}{|c|}{ System } & \multicolumn{6}{|c|}{ Bulk modulus, B (in GPa) } \\
\hline & & \multirow[b]{2}{*}{ This study } & \multicolumn{3}{|c|}{ Exp. } & \multicolumn{2}{|c|}{ Reported values } \\
\hline & & & Ref.8 & Ref9 & Ref. 10 & Ref. 1 & Ref. 27 \\
\hline \multirow[t]{16}{*}{ III-V } & $\mathrm{BN}$ & 367.838 & 367 & 346 & 367 & 351.2 & 152.06 \\
\hline & BP & 283.616 & 165 & 165 & 166 & 154.1 & 131.49 \\
\hline & BAS & 271.536 & & 138 & 138 & & 118.7 \\
\hline & $\mathrm{BSb}$ & 248.398 & & & & & \\
\hline & AlN & 104.847 & & & & & \\
\hline & AlP & 78.982 & 86 & 80.5 & 86.7 & 86.3 & 87.77 \\
\hline & AlAs & 75.669 & 77 & 74 & 78.3 & 78.3 & 79.08 \\
\hline & $\mathrm{AlSb}$ & 70.701 & 58.2 & 54.1 & 57 & 59 & 58.45 \\
\hline & $\mathrm{GaN}$ & 102.363 & & & & & 133.58 \\
\hline & $\mathrm{GaP}$ & 74.159 & 88.7 & 81.5 & 86.7 & 86.3 & 86.34 \\
\hline & GaAs & 70.944 & 74.8 & 72.4 & 76.1 & 76.1 & 75.12 \\
\hline & GaSb & 66.024 & 57 & 55.4 & 57.8 & 59.6 & 54.86 \\
\hline & $\mathrm{InN}$ & 81.515 & & & & & 107.59 \\
\hline & InP & 63.394 & 71 & 60.8 & 67 & 68.7 & 69.19 \\
\hline & InAs & 61.299 & 60 & 56.3 & 61 & 62.8 & 62.11 \\
\hline & InSb & 58.085 & 47.4 & 44 & 47.1 & 49.4 & 47.88 \\
\hline \multirow[t]{15}{*}{ II-VI } & $\mathrm{BeO}$ & 224.855 & & & & & 303.17 \\
\hline & $\mathrm{BeS}$ & 160.628 & & 120 & & & 113.11 \\
\hline & $\mathrm{BeSe}$ & 144.900 & & 105 & & & 96.55 \\
\hline & BeTe & 126.759 & & 78 & & & 68.81 \\
\hline & $\mathrm{ZnO}$ & 94.129 & & & & & 146.19 \\
\hline & $\mathrm{ZnS}$ & 68.428 & 77.1 & 73.3 & 78.1 & 72 & 75.31 \\
\hline & $\mathrm{ZnSe}$ & 63.052 & 62.4 & 65.1 & 66.5 & 63.9 & 65.3 \\
\hline & ZnTe & 57.211 & 51 & 51.9 & 51.2 & 52.2 & 55.74 \\
\hline & $\mathrm{CdO}$ & 74.270 & & & & & \\
\hline & $\mathrm{CdS}$ & 56.550 & 62 & 53.2 & 60.3 & 59.5 & 56.79 \\
\hline & $\mathrm{CdSe}$ & 52.866 & 53 & & 52.6 & 53.9 & 49.67 \\
\hline & CdTe & 48.938 & 42.4 & 40.2 & 41.2 & 44 & 43.32 \\
\hline & $\mathrm{HgS}$ & 51.350 & & & & & 56.52 \\
\hline & $\mathrm{HgSe}$ & 48.268 & 50 & & 51.9 & 53 & 49.52 \\
\hline & $\mathrm{HgTe}$ & 45.091 & 42.3 & & & 45.7 & 41.87 \\
\hline
\end{tabular}

Group properties are clearly reflected in the results. The magnitude of bulk modulii follows the order $\mathrm{BeO}>$ $\mathrm{BeS}>\mathrm{BeSe}>\mathrm{BeTe} ; \mathrm{ZnO}>\mathrm{ZnS}>\mathrm{ZnSe}>\mathrm{ZnTe} ; \mathrm{CdO}>\mathrm{CdS}>\mathrm{CdSe}>\mathrm{CdTe}$ and $\mathrm{HgS}>\mathrm{HgSe}>\mathrm{HgTe}$ in $\mathrm{II}-\mathrm{VI}$ semiconductors; and $\mathrm{BN}>\mathrm{BP}>\mathrm{BAs}>\mathrm{BSb}$; AlN>AlP>AlAs>AlSb; GaN> GaP> GaAs> GaSb and InN> $\mathrm{InP}>\mathrm{InAs}>\mathrm{InSb}$ in III-V semiconductors. For any system containing element(s) going down a group, the bulk modulus decreases. This is due to increase in size of the atom and also due to increase in ionicity caused by increasing bond length.

It is also interesting to note that compounds involving the elements from the carbon row exhibit high bulk moduli. For example BN (367.83 GPa), AlN (104.87 GPa), GaN(102.36 GPa), InN(81.51 GPa), BeO (224.85 $\mathrm{GPa}), \mathrm{ZnO}(94.12 \mathrm{GPa}), \mathrm{CdO}(74.27 \mathrm{GPa}$ ) etc. have higher values of bulk modulus. In case of $\mathrm{BeO}, \mathrm{BeS}, \mathrm{ZnO}$, and $\mathrm{CdO}$ the experimental values, to the best of our knowledge, are not available, so we have quoted the calculated values, which appear to be reasonable as they agree well with other reported values. For $\mathrm{CdO}, \mathrm{BSb}$ too, reported values are not available.

The high values of bulk modulus of compounds made up of C-row element(s) might be due to non-availability of p-sub shells in the core of atoms of such elements which allows valence electron orbitals to penetrate deeper while forming bonds with atoms of other elements leading to formation of strong bonds, and hence higher bulk

DOI Number: https://doi.org/10.30780/specialissue-ICAASET021/017

pg. 93

Paper Id: IJTRS-ICAASET2021-017

@2017, IJTRS All Right Reserved, www.ijtrs.com 
moduli. With the increase in number of $\mathrm{p}$ - sub shells, the bond between atoms of the systems weakens and the bulk modulus decreases.

The ionicity and metallicity too appear to affect bulk modulus. Its magnitude decreases with the ionicity, the order, in general, as we move from group III -V to II-VI semiconductors. However, for a given cation the ionicity decreases as the anion goes down the group. The bulk modulus follows the same trend indicating that some other factors must play the role to balance the effect of ionicity. Metallization energy decreases [28] as one goes down a group and it causes decrease in bulk modulus.

\section{CONCLUSION}

Bond hardness of binary semiconductors been calculated. The idea inclusion of covalent and ionic contributions to the bulk modulus through bond hardness has been utilised which appear logical. Linear correlation between bulk modulus and bond hardness, proposed for III-V and II-VI semiconductors. Bulk modulus of CdO and BSb has been predicated for the first time. The proposed relation has also been utilised to predict the bulk modulus of III-V and II-VI semiconductors' which is in reasonable agreement with the reported value, and its applicability can also be extended to other ternary and quaternary alloys.

\section{REFERENCES}

[1] V. Kumar, J. K. Singh and G. M. Prasad, "Elastic properties of elemental, binary and ternary semiconductor materials", Ind. J. Pure \& Appl. Physics, vol. 53, pp. 429-435, 2015.

[2] M. S. Dutta, M. K. Pathak and P. Mahto, "Bulk modulus of group-IV and its compound semiconductors", J. Alloys and Comp., vol. 695, pp. 3547-3551, 2017.

[3] A. S. Verma, "Extant ionic charge theory for bond orbital model based on the tight binding method: A semi-empirical model applied to wide band gap II-VI and III-V semiconductors" Material Science in Semiconductor Processing, vol. 29, pp. 2-15, 2015.

[4] S. B. Mirov, "Erbium laser-pumped continuous wave microchip $\mathrm{Cr}^{2+}: \mathrm{ZnS}$ and $\mathrm{Cr}^{2+}$ : ZnSe laser", Opt. Lett., vol. 27, pp.909-911 2002.

[5] S. Zhang, D. Li, J. Y. Li, Z. Y. Fang, X. L. Fu, and J. Xiao, Z. J. Peng, " Self assembly of tetrapod shaped Cds nanostructures into 3D networks by a transverse growth process" Nanotechnology, vol. 22(17), pp. 175601, 2011.

[6] A. H. Reshak, "First principle calculation of the linear and non-linear optical response for $\mathrm{GaX}(\mathrm{X}=\mathrm{As}, \mathrm{Sb}$, P)”, Eur. Phys. J. B-Condensed matter, vol. 47, pp. 503-508, 2005.

[7] O. Boyraz, B. Jalali, "Demonstration of silicon Raman Laser", Optical Express, vol. 12(21), pp. 52695273, 2004.

[8] D. R. Lide (Ed.), Hand book of Chemistry and Physics $80^{\text {th }}$ ed., CRC Publication 1999-2000; M. Weber ( Ed.), Handbook of Optical Materials (CRC Publication) 2003.

[9] V. Kumar and A. K. Shrivastava, and V. Jha,"Bulk modulus and microhardness of tetrahedral semiconductors”, J. Phys. Chem. Solids, vol. 71, pp. 1513-1520, 2010.

[10] S. K. Gorai, "Estimation of bulk modulus and microhardness of tetrahedral semiconductors", J. of Phys. Conference Series, vol. 365(1), pp. 012013(1-4), 2012.

[11] J. N. Plendl, S. S. Mitra, and P. J. Gielisse, "Compressibility, cohesive energy and hardness of non metallic solids", Phys. Status Solidi, vol. 12, pp. 367-374, 1965.

[12] A. S. Verma, "Correlation between ionic charge and optical properties of Zinc blende and complex crystal structured solids” Phys. Stat. Sol.(b), vol. 246(1), pp. 192-199, 2009).

[13] L. Garbato and A. Rucci, "Microhardness of tetrahedrally bonded semiconductors", Phil. Mag., vol. 35, pp. 1681-1684, 1977.

[14] K. Li, X. Wang, F. Zhang and D. Xue, "Electronegativity identification of Nobel superhard materials", Phys. Rev. Lett., vol. 100, pp. 235504 (1-4), 2008.

[15] Y. - J. Wang and C. - Y. Wang, "Mechanical properties and electronic structure of superhard diamond like BC $_{5}$ : A first principles study”, J. Appl. Phys., vol. 106, pp. 043513(1-12), 2009.

[16] X. - J. Guo, B. Xu, Z. - Y. Liu, D. - L. Yu., J. - L. He, and L. - C. Guo, “ Theoretical hardness of wurtzite structured semiconductors" Chin. Phys. Lett., vol. 25(6), pp. 2158-2160, 2008.

[17] H. - Y. Chung, M. B. Weinberger, J. B. Levine, A. Kavner, J. - M. Yang, S. H. Tolbert and R. B. Kaner, “ Synthesis of ultra-incompressible hard material" Science, vol. 316, pp. 436- 439, 2007.

[18] R. W. Cumberland, M. B. Weinberger, J. J. Gilman, S. M. Clark, S. H. Tolbert and R. B. Kaber, “ Osmium diboride an ultra-incompressible hard material” J. Am. Chem. Soc. Vol. 127(20), pp. 7264-7725, 2005.

[19] U. Lundin, L. Fast, L. Nordstrom, B. Johansson, J. M. Wills and O. Erikson, "Transition metal dioxide with a bulk modulus comparable to diamond", Phys. Rev. B, vol. 57(9), pp. 4979-4982, 1998.

[20] J. C. Phillips, "Dielectric definition of electronegativity” Phys. Rev. Lett., vol. 20, pp. 550-553, 1968 ; “ Ionicity of chemical bond in crystal" Rev. Mod. Phys., vol. 42(3), pp. 317-356, 1970.

[21] J. A. Van Vechten, "Quantum dielectric theory of electronegativity in covalent systems" Phys. Rev., vol. 182(3), pp. 891-905, 1969.

[22] J. C. Phillips and J. A. Van Vechten, “ Dielectric classification of crystal structures, ionization potential and band structure" Phys. Rev. Lett., vol. 22(14), pp. 705-708, 1969 " New sets of tetrahedral co-valent radii”, Phys. Rev. B, vol. 2(6), pp. 2160-2167, 1970.

[23] B. F. Levine, "A new contribution to the non linear optical susceptibility arising from unequal atomic radius”, Phys. Rev. Lett., vol. 25(7), pp. 440-442, 1970 ; “d- electron effect on bond susceptibility and 
ICAASET-2021, 20-21 May, 2021, K.R. Mangalam University, Gurugram

International Journal of Technical Research \& Science (Special Issue) ISSN No.:2454-2024 (online)

ionicities" Phys. Rev. B, vol. 7(6), pp. 2591-2600, 1973 ; “ Bond susceptibility and ionicities in complex crystal structures”, J. Chem. Phys., vol. 59(3), pp. 1463-1486, 1973.

[24] N. E. Christensen, S. Satpathy, Z. Pawlowska, "Bonding and ionicity in semicondcutors", Phys. Rev. B, vol. 36(2), pp. 1032-1050, 1987.

[25] A. Garcia and M. L. Cohen, "First-principal ionicity scales. I. charge asymmetry in the solid state ", Phys. Rev. B, vol. 47(8), pp. 4215-4220, 1993.

[26] Communicated to J. Of American Chemical Society

[27] M. k. Pathak, M. S. Dutta, R. K. Ranjan and P. Mahto, "Bond Hardness and Mechanical Properties of $\mathrm{A}^{\mathrm{N}} \mathrm{B}^{8-\mathrm{N}}$ semiconductors and their alloys", Int J. of Engineering, Science and Mathematics, vol. 6(6), pp. 357-388, 2017.

[28] K. Y. Li and D. F. Xue, "Hardness of materials: Studies at levels from atoms to crystals", Chin. Sc. Bulletin, vol. 54(1), pp. 131-136, 2009. 